УДК 330.341

\title{
ОРГАНИЗАЦИЯ В РЕСПУБЛИКЕ БЕЛАРУСЬ КЛАСТЕРА ИСПОЛЬЗОВАНИЯ ВТОРИЧНЫХ МОЛОЧНЫХ РЕСУРСОВ
}

\author{
Е.И. БАХМАТОВА \\ аспирант Белорусского национального технического университета, г. Минск
}

\begin{abstract}
Аннотация
В статье рассматриваются возможности реализации в Республике Беларусь кластерного подхода в сочетании с централизацией производственных мощностей по переработке вторичных молочных ресурсов. Определены институциональные особенности организации кластера использования вторичных молочных ресурсов, а также ключевые роли государственных органов управления в стимулировании кластерной инициативы в обозначенном направлении.
\end{abstract}

Abstract

Possible implementation of cluster approach in combination with centralization of the capacities of processing secondary dairy resources in the Republic of Belarus is considered. Institutional features of the treating secondary dairy resources cluster and also key roles of the government in stimulating cluster initiative are defined.

\section{ВВЕДЕНИЕ}

Расширение ассортимента и повышение добавленной стоимости готовой продукции на основе вторичных молочных ресурсов в Республике Беларусь невозможны без консолидации усилий предприятий-переработчиков и вовлечения в процессы производства и потребления разнообразных отраслей пищевой, фармацевтической, химической и топливно-энергетической промышленности. Интеграция молокоперерабатывающих организаций, специализированных предприятий по централизованной переработке вторичных молочных ресурсов и многочисленных потенциальных промышленных потребителей вторичного молочного сырья должна быть реализована в форме, позволяющей:

- на постоянной основе объединять усилия большого количества организаций различных форм собственности и видов деятельности на всех этапах создания добавленной стоимости готовой продукции на основе вторичного молочного сырья;

- сохранять организациями-участниками интеграционного образования свою экономическую независимость и хозяйственную самостоятельность;

- коллективно принимать решения;

- предоставлять возможности для участия в интеграционном образовании инфраструктурных организаций, обслуживающих процессы создания потребительской ценности.

В настоящее время в Республике Беларусь происходит усиление концентрации в молочной отрасли промышленности путем присоединения контролируемых государством мелких и убыточных предприятий к более крупным и эффективным. Например, если в 2009 г. в молокоперерабатывающей отрасли работало 143 компании, то в 2014 г. уже только 40. В то же время происходит ужесточение конкуренции на внутреннем рынке в силу достижения высокой степени насыщения национального рынка молочной продукцией.

Взаимодействие коммерческих организаций на условиях одновременно конкуренции и сотрудничества является уникальной особенностью такой современной формы интеграции экономических субъектов, как кластер. На основе грамотного сочетания централизованного и кластерного подходов в Республике Беларусь могут быть созданы эффективные условия для интеграции необходимых объемов материального, финансового, информационного, интеллектуального, административного и инновационного ресурсов. Реализация кластерного подхода в сочетании с централизацией производственных мощностей по переработке вторичных молочных ресурсов имеет хорошие перспективы для достижения следующих конкурентных преимуществ как на уровне отдельных организаций, отраслей промышленности, так и на уровне национальной экономики в целом:

- повышение уровня глубины и комплексности переработки вторичных молочных ресурсов, добавленной стоимости готовой продукции на их основе;

- производство широкого ассортимента готовой продукции на основе вторичного молочного сырья, полностью удовлетворяющего структуре потребности в нем, в том числе на международных рынках сбыта;

- повышение уровня наукоемкости отраслей, вовлеченных в процессы использования вторичных молочных ресурсов;

- повышение инновационного потенциала производства;

- консолидация финансовых ресурсов и диссипация рисков;

- приобретение высокотехнологичной дорогостоящей баромембранной техники и технологии;

- импортозамещение в таких стратегических направлениях, как производство сухих заменителей цельного молока и обогатителей кормов, спортивного питания, биологически активных добавок на основе лактулозы и т.д.;

- диверсификация экспортного рынка готовой продукции на основе вторичного молочного сырья в восточном направлении. 
В связи с перечисленными выше потенциальными преимуществами особую актуальность приобретает рассмотрение вопроса организации кластера использования вторичных молочных ресурсов в Республике Беларусь.

\section{РЕЗУЛЬТАТЫ И ИХ ОБСУЖДЕНИЕ}

В зависимости от того, чьи интересы и финансовые ресурсы выступают доминирующей движущей силой, выделяют два основных пути организации кластера, определяющих особенности разработки и реализации государственной кластерной политики поддержки и содействия. Первый путь «снизу-вверх» характеризует скоординированные инициативы по организации коммерческих кластеров, предпринимаемые и финансируемые наиболее заинтересованными организациями-участниками корпоративного взаимодействия, фактическая готовность и способность которых к самоорганизации достаточно высока. Создание коммерческого кластера «снизу-вверх» предполагает предоставление дифференцированных государственных мер поддержки и содействия на конкурсных началах.

«Нисходящий» путь характеризует все государственные инициативы, способствующие объединению в кластеры, которые на ранних стадиях своего жизненного цикла функционируют при доминирующем интересе и влиянии государственных органов управления и финансируются, преимущественно за счет средств государственного бюджета или специализированных фондов. Несмотря на активную критику данного пути организации кластера, в его пользу свидетельствует реальная экономическая практика: большинство современных устойчиво функционирующих как национальных, так и региональных кластеров в Нидерландах, Швеции, Великобритании, Австрии, Бельгии, Германии и Испании прошли именно «нисходящий» путь развития [1]. Как формируемый «сверху-вниз» национальный, так и коммерческий кластеры с течением времени могут успешно трансформироваться в оптимальную с точки зрения соотношения государственного вмешательства и заинтересованности бизнеса смешанную модель.

Для экономики Республики Беларусь на текущем этапе наиболее целесообразным является нисходящий путь организации кластера использования вторичных молочных ресурсов. Это обусловлено следующими причинами: вопервых, организация кластера затрагивает национальные интересы Республики Беларусь во многих областях; вовторых, существуют неблагоприятные факторы деловой среды, препятствующие самостоятельному появлению устойчивых сетей взаимодействия: доминирование государства над наукой и бизнесом при отсутствии обратных связей, узость поля горизонтальных связей, высокий уровень сопротивления изменениям и крайняя разобщенность социума. В дополнение отметим, что в международной практике набирают популярность «золотые правила» кластерной политики, сформулированные К. Кетельсом, которые утверждают: государство не должно селективно отбирать потенциальных участников кластеров, их проекты и на конкурсной основе определять приоритеты для целей субсидирования; государство может софинансировать и инициировать кластеры; государство должно поддерживать существующие и зарождающиеся кластеры во всех секторах экономики (а не только в передовых или быстрорастущих), обеспечить на уровне каждого кластера доступную статистику, а также быть готовым выполнять рекомендации [2].

Таким образом, инициатором организации национального кластера использования вторичных молочных ресурсов должны выступать государственные органы управления. Стимулирование участия в кластере бизнеса должно в перспективе содействовать его трансформации в оптимальный смешанный тип.

Цели объединения участников в кластер использования вторичных молочных ресурсов заключается в следующем:

- формирование оптимальной с точки зрения объемов выработки вторичного молочного сырья структуры его переботки, обеспечивающей полное глубокое комплексное использование вторичного молочного сырья и производство на его основе конкурентоспособной, высокотехнологичной, импортозамещающей продукции, относящейся ко второму и третьему уровню добавленной стоимости;

- повышение конкурентоспособности и экономического потенциала участников кластера за счет реализации потенциала эффективного взаимодействия, связанного с их участием в процессах переработки вторичных молочных ресурусов, включая расширение доступа к инновациям, технологиям, «ноу-хау», специализированным услугам и высококвалифицированным кадрам, а также снижением транзакционных издержек, обеспечивающим формирование предпосылок для реализации совместных кооперационных проектов и продуктивной конкуренции;

- улучшение внешнеэкономической интеграции и рост международной конкурентоспособности участников кластера за счет включения кластера и его участников в глобальные цепочки создания добавленной стоимости.

Ключевые задачи создания и устойчивого функционирования кластера переработки включают:

- моделирование организационной структуры кластера;

- выбор организационной формы функционирования кластера;

- определение организационной формы объединения управляющих кластером;

- определение прав и обязанностей участников кластера и управляющих им;

- описание формальной организации процессов взаимодействия и принятия решений в пределах кластера;

- разработка пакета организационных документов создания кластера;

- формирования в составе совета кластера экспертных комиссий по содействию поиску, обоснованию новых и проведению экспертизы существующих инвестиционно-инновационных проектов;

- активизация научно-исследовательской деятельности специализированных организаций и инновационной деятельности промышленных предприятий - потенциальных участников кластера с целью поиска и обоснования инновационных идей переработки вторичных молочных ресурсов;

- формирование перечня ключевых перспективных инвестиционно-инновационных проектов; 
- оценка потенциала и определение стратегических направлений использования вторичных молочных ресурсов в разрезе областей Республики Беларусь;

- оценка ресурсного обеспечения, необходимого для реализации предложенных проектов;

- разработка организационно-экономического механизма содействия формированию и устойчивому функционированию кластера, т.е. выработка экономических инструментов и рычагов стимулирования участников кластера к интеграционному процессу и активному участию в процессах поиска, обоснования и реализации наиболее перспективных направлений использования вторичных молочных ресурсов в Республике Беларусь;

- систематическая оценка аллокативной, экономической, ресурсной, коммерческой, социальной, бюджетной, экологической, инновационной и научно-технической эффективности кластера переработки вторичных молочных ресурсов.

Инновационная активность, предпринимательская инициатива и адаптивность являются двигателями развития кластера. Наиболее успешные кластеры основаны на алгоритмах взаимодействия, способных ускорить движение идей, инноваций и информации между их участниками. Алгоритмы получения и распространения новых знаний, играющие определяющую роль в обеспечении успешного запуска и устойчивого функционирования кластера, во многом зависят от его организационной структуры и формы функционирования. Другими словами, структура кластера определяет стратегию его развития. Потенциальными участниками кластера переработки вторичных молочных ресурсов являются:

- государственные органы управления;

- объединение управляющих кластером;

- фонд для аккумулирования финансовых ресурсов кластера;

- хозяйствующие субъекты базовых отраслей кластера: молокоперерабатывающие производства, а также создаваемые в Республике Беларусь предприятия централизованного сбора и переработки вторичного молочного сырья;

- хозяйствующие субъекты структурообразующих отраслей кластера, способные использовать вторичное молочное сырье с целью выработки на его основе готовой продукции: предприятия мясо-молочной, хлебобулочной, кондитерской, спирто-водочной, косметической, фармацевтической, топливной отраслей промышленности, производства детского, спортивного питания, заменителей цельного молока;

- потенциально новая для Республики Беларусь отрасль машиностроительной индустрии: производство вакуумвыпарных установок, оборудования электродиализа и ультрафильтрации, нанфильтрационных и обратноосмотических мембран;

- инфраструктурные организации: научно-технические, образовательные, инновационные, финансовокредитные, транспортные и др.

Модель организационной структуры кластера представлена на рисунке 1. циал для:

Представленная на рисунке 1 модель организационной структуры кластера демонстрирует его высокий потен-

- формирования в перспективе тесных системно развивающихся устойчивых связей между базовыми и структурообразующими отраслями кластера, структурообразующими отраслями и инфраструктурными организациями;

- развитие сбалансированных отношений конкуренции и сотрудничества между кластерными структурообразующими отраслями областей Республики Беларусь;

- повышения инновационного потенциала организаций-участников кластера на основе поиска и реализации инвестиционно-инновационных проектов переработки вторичного молочного сырья.

Таким образом, предлагаемый к реализации кластер переработки вторичных молочных ресурсов в целом соответствует распространенным в мировой практике признакам кластерного образования.

Возможны два основных сценария создания кластера использования вторичных молочных ресурсов в Республике Беларусь: дирижистский и либеральный. Оба сценария предполагают инициирование процесса кластеризации «сверху-вниз». Дирижистский путь создания кластера позволяет преодолеть на начальных этапах феномен сопротивления инновациям, однако, он сопряжен с проблемой формального отношения бизнеса к процессам кластеризации. Предпочтительным является либеральный путь, основанный на диалоге корпоративного и государственного уровней управления, который позволяет уже на начальных этапах кластеризации реализовать наиболее оптимальную модель создания смешанного кластера.

Выбор организационной формы функционирования кластера также имеет важное значение, поскольку она определяет условия вступления, порядок взаимодействия, правила сотрудничества, права и обязанности участников, которые должны быть формализованы и структурированы, чтобы гарантировать прозрачность, здоровую конкуренцию, равнозначные условия. Утвержденная Постановлением Совета Министров Республики Беларусь от 16.01.2014 № 27 Концепция формирования и развития инновационно-промышленных кластеров в Республике Беларусь и мероприятий по ее реализации (далее Концепция) предусматривает следующие две возможные организационные формы функционирования кластера:

- простое товарищество на основании соответствующего договора о совместной деятельности;

- организация кластерного развития в форме юридического лица, организационно-правовая форма которого не уточняется. 


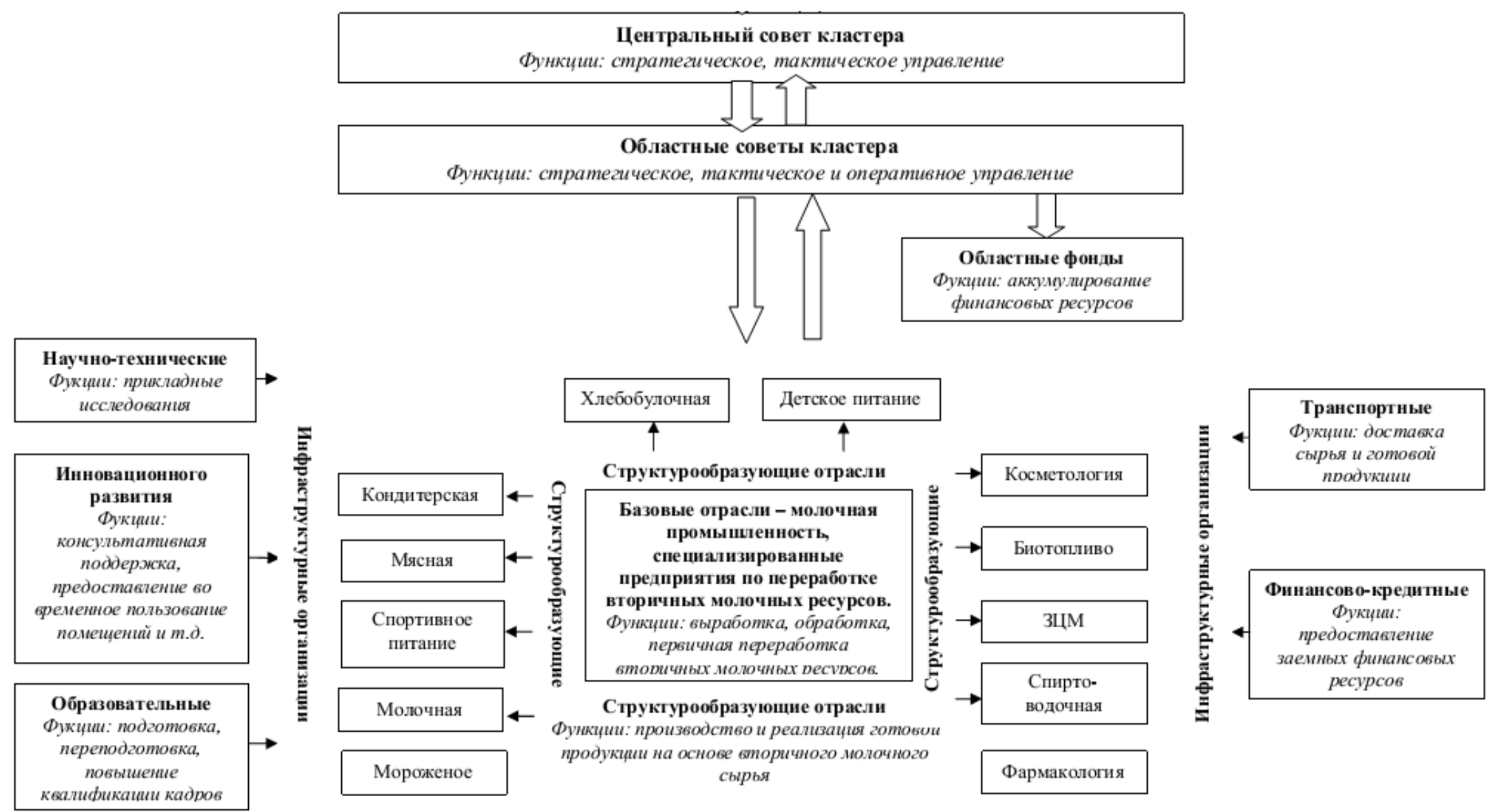

Рисунок 1 - Модель организационной структуры кластера переработки вторичных молочных ресурсов 
Предлагаемые критерии выбора формы организации кластера охарактеризованы в таблице 1:

Таблица 1 - Критерии выбора организационной формы функционирования кластера

\begin{tabular}{|c|c|c|}
\hline Критерий & Простое товарищество & Организация кластерного развития \\
\hline Количество участников & Значительное & Незначительное \\
\hline $\begin{array}{c}\text { Цель деятельности организаций- } \\
\text { участников кластера }\end{array}$ & $\begin{array}{c}\text { извлечение прибыли или не связан- } \\
\text { ная с предпринимательской дея- } \\
\text { тельностью цель }\end{array}$ & Незначительное прибыли \\
\hline $\begin{array}{c}\text { Количество цепочек создания стои- } \\
\text { мости }\end{array}$ & Значительное & извение \\
\hline $\begin{array}{c}\text { Тип экономических связей между } \\
\text { участниками }\end{array}$ & $\begin{array}{c}\text { разнообразные как горизонтальные, } \\
\text { так и вертикальные связи }\end{array}$ & $\begin{array}{c}\text { преобладают только горизонтальные } \\
\text { или только вертикальные связи }\end{array}$ \\
\hline $\begin{array}{c}\text { Количество связей между участни- } \\
\text { ками }\end{array}$ & $\begin{array}{c}\text { значительно меньше количества } \\
\text { участников }\end{array}$ & $\begin{array}{c}\text { примерно равняется количеству } \\
\text { участников }\end{array}$ \\
\hline
\end{tabular}

В соответствии с предложенными выше критериями, наиболее предпочтительной формой организации кластера переработки вторичных молочных ресурсов является простое товарищество, поскольку:

- кластер объединяет большое количество как коммерческих, так и некоммерческих организаций;

- базовые и структурообразующие отрасли-участники кластера относятся к различным цепочкам создания добавленной стоимости;

- между участниками кластера могут возникать разнообразные экономические, как вертикальные, так и горизонтальные связи;

- некоторые структурообразующие отрасли-участники кластера никак между собой не взаимодействуют.

Концепция предлагает только одну возможную организационную форму объединения управляющих кластером - совет. При этом в качестве участников совета в Концепции упоминаются только руководители организацийучастников кластера. В связи с тем, что кластер использования вторичных молочных ресурсов создается в масштабах национальной экономики Республики Беларусь в целом и не имеет территориальной локализации, включение в состав совета руководителей всех его организаций-участников невозможно. Для решения данной проблемы предлагается создать областные советы управляющих кластером. В составе советов также предлагается формировать временные экспертные комиссии с целью делегирования им функций поиска и обоснования новых и экспертизы предлагаемых субъектами хозяйствования инвестиционно-инновационных проектов.

Организация в Республике Беларусь кластера использования вторичных молочных ресурсов с ключевой ролью предприятий по централизованной переработке предполагает разработку и применение кластерной политики, направленной на содействие и поддержку кластерных инициатив в обозначенном направлении.

В распоряжении государственных органов управления имеется разнообразный инструментарий поддержки, содействия и стимулирования бизнеса с целью его вовлечения в интеграционные процессы. Наиболее успешные и актуальные практики взаимодействия государства, бизнеса и общества относительно кластерной модели развития экономики в целом и использования вторичных молочных ресурсов охарактеризованы ниже.

Одна из ключевых базовых ролей государства в формировании предпосылок возникновения и успешной реализации кластерных инициатив заключается в изыскании и предоставлении ресурсов для обеспечения экономического роста национальной экономики в целом, что подразумевает доступность всех уровней образования, качественную развитую «тяжелую» (коммуникации) и «легкую» (финансовые и нефинансовые бизнес-услуги) инфраструктуры, безопасные условия жизнедеятельности, сохранность здоровья населения и т.д.

Следующая ключевая роль государственных органов управления заключается в применении в отношении бизнес-сообщества эффективных методов управления сопротивлением инновациям. Кластерная модель экономики требует от организаций существенных прогрессивных изменений, процесс реализации которых не должен быть стихийным. Наиболее известные методы успешного управления изменениями, такие как модель Л. Гейнера, метод адаптивных изменений И. Ансоффа, акцентируют основное внимание на необходимости обсуждения проблем и путей внедрения изменений со всеми участниками видоизменяемой системы управления. В контексте кластерного развития методом сопротивления изменениям является использование диалоговых бизнес-площадок, которые на практике могут реализованы в виде заседаний рабочих групп, советов, проведения совещаний и т.д.

В Республике Беларусь, в частности, в соответствии с Концепцией предусматривается создание и организация деятельности рабочих групп для содействия формированию инновационно-промышленных кластеров в облисполкомах (Минском горисполкоме), в том числе с участием представителей указанных облисполкомов (Минского горисполкома), Министерства экономики, Государственного комитета по науке и технологиям, отраслевых министерств и концернов, бизнес-ассоциаций, на базе подчиненных организаций (участников бизнес-ассоциаций), в которых намечается формирование таких инновационно-промышленных кластеров. Организация заседаний рабочих групп с участием представителей власти, науки и бизнеса является важнейшим мероприятием на всех этапах жизненного цикла кластера, стимулирующим кластерную инициативу, а также позволяющим систематически проводить мониториг проблем и контроль устойчивости функционирования. Однако обсуждение вопросов кластеризации должно проводится на базе результатов совместных исследований бизнес-среды, формирования перечня наиболее перспективных для реализации инвестиционно-инновационных проектов. 
Положительное влияние на потенциал кластеризации оказывает реализация государственной политики, направленной, прежде всего, на поддержку и поощрение участия в кластере, а не предотвращение, препятствование или ограничение деятельности незаинтересованной части бизнес-сообщества. Большие перспективы для устойчивого функционирования кластера создает государственная политика, которая служит стимулом, побуждает, поощряет, поддерживает и содействует инновационно-интеграционным процессам. Стимулирующая государственная кластерная политика гарантирует установление тесных продуктивных взаимосвязей между разрозненными элементами экономической системы, равенство и взаимный учет интересов ее участников в процессе достижения общей цели экономического развития и индивидуальных конкурентных преимуществ каждого из них.

В контексте поддерживающей и содействующей государственной политики целесообразно отдельно упомянуть стимулирование предпринимательской инициативы и активизацию инновационной деятельности. Инновации и предпринимательство - двигатели развития кластера. Принимая во внимание мировой опыт, большинство кластерных инициатив было сформировано коммерческими организациями с целью увеличения масштабов деятельности, расширения географии поставок, выхода на новые рынки сбыта или в ответ на ослабление рыночной позиции организации на этапе завершения ее жизненного цикла. Несмотря на то, что предпринимательская инициатива и активность инновационной деятельности зависят во многом от интеллектуального капитала страны, они могут быть усилены преднамеренной государственной политикой стимулирования.

С целью создания максимально благоприятных условий для функционирования кластера переработки вторичных молочных ресурсов необходимо ввести в действующее законодательство понятие резидента инновационнопромышленного кластера с целью возможности их отнесения к определенной категории налогоплательщиков. Такая мера позволит распространить на инновационно-территориальные кластеры меры такие меры государственной поддержки и содействия, как специальный налоговый и таможенный режимы.

Специальный налоговый режим в отношении участников кластера использования вторичных молочных ресурсов может предполагать:

- уменьшение ставки налога на прибыль на 50 процентов от ставки, установленной пунктом 1 статьи 142 Налогового Кодекса;

- освобождение от уплаты налога на прибыль по видам готовой продукции на основе вторичного молочного сырья;

- освобождение от налога на недвижимость по зданиям и сооружениям;

- уменьшение налога на добавленную стоимость на 50 процентов от подлежащей уплате суммы указанного налога с оборотов по реализации на территории Республики Беларусь импортозамещающей готовой продукции на основе вторичного молочного сырья в соответствии с перечнем импортозамещающих товаров;

- предоставление инвестиционного налогового кредита по налогу на прибыль для малых и средних организаций на период до 5 лет.

Последний из указанных выше инструментов может представлять особую актуальность для малого и среднего бизнеса в сфере торговли спортивным питанием в Республике Беларусь в случае успешной реализации инновационноинвестиционного проекта производства концентрата (50-89\%) и изолята сывороточного белка. Кредит может предоставляться организациям, доля продукции отечественного производства в которых достигает некоторого фиксированного процента.

Специальный таможенный режим для резидентов кластера использования вторичных молочных ресурсов также должен существенно уменьшать объем таможенных пошлин и платежей, подлежащих к уплате при ввозе на таможенную территорию РБ необходимых для производства сырья, материалов и оборудования.

Основным экономическим инструментом реализации стимулирующей государственной политики в контексте кластеризации является финансирование реализации кластерных проектов. Немногие организации кластерного развития способны самостоятельно финансировать свою текущую и проектную деятельность за счет членских взносов и совместно аккумулируемых в форме фондов финансовых ресурсов. Доступность внешних источников финансирования и возможность распределения затрат на функционирование играет ключевую роль для кластерных инициатив. Ответственность государственных органов управления включается разработку долгосрочных планов субсидирования, льготного кредитования, выделения грантов, необходимых для устойчивого функционирования кластера.

В Концепции предусмотрено выделение на безвозмездной и безвозвратной основе субсидий организациям и центрам кластерного развития на разнообразные цели: проведение маркетинговых исследований, приобретение лицензий и патентов, повышение квалификации персонала, управление качеством, проведение испытаний и т.д. Ключевым фактором успеха кластера использования вторичных молочных ресурсов является технико-технологический базис. В качестве решающего импульса создания и развития кластера должно стать субсидирование затрат базовых организаций кластера использования вторичных молочных ресурсов на приобретение баромембранной техники и освоение технологии.

Одним из популярных методов финансирования инновационной деятельности является создание венчурных фондов. Новые идеи и инновации, формирование новых видов деловой активности и расширение масштабов существующих являются важнейшими стратегическим направления развития кластера. Зарождающиеся кластеры включают много новых и потенциальных предпринимателей. Кластерная ориентация инвестирования нуждается в разнообразии источников финансирования стартового капитала, фондов разработки продукта, венчурных фондов, оборотного капитала для более зрелых и расширяющихся фирм. Правительственная поддержка может быть оказана, настроив соответствующие механизмы финансирования и гарантировав минимальные бюрократические инструкции и препятствия, чтобы получить доступ к этим фондам. 
В контексте кластера использования вторичных молочных ресурсов предлагается инициировать создание фонда развития и обязать организации-участников кластера перечислять в фонд фиксированный процент от части льготируемой прибыли. На этапе создания кластера и центрального фонда поддержки его развития, помимо прибыли участников кластера, фонд может быть частично сформирован за счет государственных финансовых средств, выделяемых на возвратной возмездной или безвозмездной основе.

Еще одна правительственная роль может заключаться в локализации и концентрации ресурсов и инвестиций с целью максимизации управленческого воздействия. Кластеры формируют рациональную основу для концентрации ресурсов с целью максимизации управленческого воздействия на экономику. Значительные инвестиции в важнейшие элементы кластера - инновационные центры, научные и технологические парки и др. - распространенный способ формирования положительной репутации кластера и привлечения новых участников. Опыт развитых стран показывает, что наиболее стремительно увеличивают свои масштабы кластеры со смешанным успехом, но достаточными инвестициями. Еще одна важная рекомендация заключается в том, что методы финансирования государством кластерных инициатив должны быть чувствительны в стадии жизненного цикла кластера. Потребности в финансировании зарождающихся кластеров значительно отличаются от потребностей зрелых. Реорганизация механизма финансирования с целью оказания адресной поддержки подходит только для создаваемых кластеров. Индустриальные парки и инкубаторы будут способствовать вовлечению в создаваемый кластер новых участников.

На стадии зарождения кластера большую эффективность приобретают конкурсные программы финансирования. Один из самых легких и действенных способов поощрить сотрудничество среди фирм и достигнуть экономии за счет расширения масштабов производства - проводить конкурс совместных проектов. Типичные цели конкурсного финансирования могут включать:

- поддержку ассоциаций предпринимательства;

- поддержку объединений поставщиков технических и организационных услуг для обучения участников кластера;

- содействие сотрудничеству малого и среднего бизнеса в целях развития существующих, создания новых рабочих мест.

Содействие формированию устойчивых взаимосвязей и участие в них может рассматриваться как отдельная государственная функция. Государству следует стремиться самостоятельно позиционировать себя как неотъемлемого участника кластерных образований, обеспечивая поддержку и содействие как в целом, так и целенаправленно, где это необходимо. Корни кластерной интеграции лежат в получивших распространение в мировой экономике в 1990-х гг. экономических процессах концентрации (укрупнения бизнеса и капитала) и кооперирования (установления длительных производственных связей) производства. Кластерные формы взаимодействия в отличие от названных выше более разнообразны, менее формализованы и предполагают совместные действия юридически независимых организаций, государства и общества в процессе генерирования идей, коммерциализация и диффузии инноваций, распространения информации и обмена опытом внутри кластера. Способность государства одновременно участвовать в кластерном взаимодействии и инспирировать его, жизненно важна для конкурентоспособных кластеров.

Из описанной выше функции вытекает следующая важная правительственная роль, которая заключается в реорганизации инфраструктурной системы поставки услуг. Как государственные, так и частные научноисследовательские, образовательные, консалтинговые, финансовые и прочие инфраструктурные организации зачастую осуществляют свою деятельность разрозненно, независимо друг от друга. В связи с этим, актуальность приобретает переориентация инфраструктурных организаций на проблемно-ориентированный подход, который опирается, прежде всего, на интересы участников кластера, а не только на достижение коммерческого, социального, научнотехнического или иного результата деятельности. Проблемно-ориентированный подход является обязательным условием эффективного вовлечения инфраструктурных организаций в кластер, т.к. предполагает делегирование им функции организатора исследовательско-аналитической работы. Такие преобразования могут быть достигнуты как на основе создания новых специализированных государственных инфраструктурных организаций-поставщиков широкого комплекса услуг участникам кластера, так и путем проведения стимулирующей разъяснительной работы среди персонала существующих организаций. Особенно важно, чтобы сотрудники кластерных инфраструктурных организаций имели производственный опыт, демонстрировали глубокое понимание проблем, технологий, рынков сбыта и потребителей организаций-участников кластера.

Результативными также могут оказаться действия государственных органов управления по реорганизации системы представления экономической информации. Широко распространена практика организации и представления статистической информации в разрезе регионов и отраслей национальной экономики. Как участникам кластера, так и центрам кластерного развития было бы полезно иметь доступ к социально-экономической информации, сгруппированной в разрезе кластера. Такого рода информация может включать уровень занятости, динамику объемов производства и реализации, запасов, финансовые результаты в отраслях-участниках кластера, перечень технологий, поставщиков и потребителей, вакансии и предложения на рынке труда, проектные нормы и нормативы, технико-экономические обоснования и т.д. Первостепенное значение имеет также доступ к мировым базам социально-экономических параметров функционирования аналогичных кластеров за рубежом. Ограниченный доступ к лучшим мировым практикам ведения бизнеса, новым источникам знания и технологического опыта, что особенно характерно для переходных экономик, представляют собой существенный барьер для поиска и выработки новых долгосрочных стратегических конкурентных преимуществ организаций-участников кластера. Часть информационной замкнутости позволяет в некоторой степени преодолевать расширенный доступ к соответствующим интернет-ресурсам. Однако бо́льшую ценность в создании предпосылок для эффективного бенч-маркетинга имеет прямое межорганизационное взаимодействие. Госу- 
дарственные органы управления могут содействовать накоплению зарубежного опыта на основе организации международных выставок, узконаправленных деловых командировок, стажировок и т.д.

Следующая правительственная функция создания сети организаций инновационного развития имеет большую популярность в странах как развитых, так и переходных экономик. В частности, в Концепции предусмотрено формирование сети центров кластерного развития на базе облисполкомов, Минского горисполкома, объединений юридических лиц и (или) индивидуальных предпринимателей (ассоциации и союзы), а также наиболее развитых научнотехнологических парков и иных организаций. В соответствии с Концепцией, предметом деятельности центров кластерного развития будет являться сопровождение кластерных проектов посредством оказания организационных, информационных и аналитических услуг участникам кластеров, в том числе оказание консалтинговых услуг (юридических, финансовых, инжиниринговых и других), поиск дополнительных источников финансирования для реализации кластерных проектов, разработка бизнес-планов, маркетинговые исследования, продвижение на рынок продукции участников кластера, организация конференций, семинаров и других информационных мероприятий для участников кластера, организация обучения и повышения квалификации кадров руководителей и специалистов участников кластера.

В обоснование значимости рассматриваемой роли отметим, что создание кластера часто сопряжено с вовлечением организаций в новые виды деятельности, которые требуют формирования и накопления технологического опыта. Поэтому информация и знания становятся ключевым фактором успеха. Кластерные организации могут извлечь значительные выгоды за счет потребления услуг узкоспециализированных организаций инновационного развития, продуктивность работы которых существенно повышается в случае участия в них существующих предпринимательских ассоциаций и союзов. Роль государства в отношении различных форм организации инновационной деятельности заключается в обеспечении неформального характера их функционирования.

Инфраструктурные преобразования касаются еще одной чрезвычайно важной компетенции государственных органов управления - целевой подготовки квалифицированных кадров. Исключая прогрессивную техникотехнологическую базу, для кластера нет ничего важнее полноценного кадрового резерва. В отношении ни каких других видов ресурсов кластеры не зависят так серьезно от государства, которое является самым крупным инвестором в сфере образования. В процессе принятия решения о кластерной инициативе бизнес оценивает доступ к трудовым ресурсам, которые обладают профессиональными компетенциями в соответствующих областях и в состоянии применить деловые навыки в особой рабочей среде кластера. В результате успех кластерной модели развития экономики ставится в прямую зависимость от способности учреждений образования быстро среагировать на появление потребности в специфических кадрах, сократить лаг с момента появления такой потребности и до момента ее удовлетворения.

В условиях кластерного развития на первый план выходит целевая подготовка узкоспециализированных специалистов. Важным моментом также является применение междисциплинарных подходов, обеспечивающих преподавание дисциплин в контексте кластерной концепции развития экономики. Образовательные стандарты регламентируют порядок разработки и утверждения учебных планов специальностей часто без привязки к конкретной отрасли экономики. Между тем, получаемые знания и навыки в дальнейшем преобразуются с учетом отраслевых особенностей и могут значительно варьироваться по отраслям и секторам экономики. Проектирование учебных планов специальностей в разрезе отраслей-участников кластера создает хорошие перспективы для повышения уровня лояльности будущих специалистов и стремления развиваться профессионально в рамках организации-участника кластера, а не становиться экономическими мигрантами.

Из рассмотренной выше функции вытекает следующая правительственная роль, которая базируется на сформулированных ранее принципах тройной спирали и предполагает установление связей между учреждениями образования и центрами кластерного развития. Вместо того, чтобы ожидать от учреждений образования своевременного и глубокого понимания кадровых потребностей участников кластера, государственные органы управления должны способствовать сотрудничеству университетов и центров кластерного развития, которые, в свою очередь, могут стать для учреждений образования ключевыми поставщиками самой актуальной информации о проблемах, потребностях участников кластера, наиболее востребованных специальностях, определяя тем самым направления развития учебных планов, обновления образовательных стандартов и т.д. В свою очередь центры кластерного развития будут иметь возможность постановки процессов организации исследований бизнес-среды, формирования стратегических направлений деятельности, решения проблем и преодоления барьеров на научные основы за счет привлечения профессорскопреподавательского персонала, организации на базе университетов практико-ориентированных площадок и т.д.

Превалирующая часть передовых фундаментальных и прикладных исследований проводится на базе государственных научно-исследовательских институтов, к участию в которых по возможности привлекаются ведущие высшие учебные заведения страны, что соответствуют теории тройной спирали. Вследствие того, что отдельные регионы страны могут испытывать недостаток в ведущих исследовательских институтах и университетах, специальные учебные заведения могут также начать рассматриваться в качестве базы для генерирования идей, проведения прикладных экспериментальных и исследований. Прикладные исследования в такого рода учебных заведениях будут носить менее глобальный характер и проводиться с учетом локальных потребностей участников кластера в регионах. Организация прикладных исследований на местном уровне также потребует дополнительного целевого финансирования на конкурсных началах. В качестве критериев выделения финансирования в данном случае должны выступать соответствие потребностям региональных экономик и высокий коммерческий потенциал для их удовлетворения. 
В качестве отдельной правительственной роли целесообразно также отметить использование кластеров как инструмента для создания благоприятного международного имиджа страны и привлечения зарубежных предпринимателей и инвесторов.

На стадии зрелости кластера большую актуальность приобретает необходимость формирования развитых экспортных сетей. Образуемые малые и средние предприятия, а также существующие участники кластера, вступающие на различных уровнях в новые цепочки создания стоимости, могут испытывать затруднения в налаживании экспортных товаропроводящих сетей. Функция государственных органов управления в данном случае заключается в содействии формированию кластерных экспортных объединений, которые в дальнейшем могут по собственной инициативе присоединиться к Белорусской торгово-промышленной палате.

В качестве заключительной функции государственных органов управления можно назвать защиту внутреннего рынка Важным инструментом защиты внутреннего рынка продукции на основе вторичных молочных ресурсов на этапе зрелости кластера может стать импортная квота на поставку отдельных видов продукции, например: сухой молочной сыворотки, спортивного питания, фармацевтической лактулозы и др.

Эффективность механизма управления на государственном уровне во многом определяется результативностью мер, предпринимаемых на корпоративном уровне управления, которые должны быть направлены в первую очередь на преодоление феномена сопротивления изменениям. Передача управленческого воздействия с целью инициации интеграционных процессов в среде потенциальных участников кластера может быть организована за счет организации специализированных структурных подразделений или временных проектных групп, ответственных за инновационный поиск, маркетинговые исследования, технико-экономическое обоснование, организацию, координацию и контроль реализации инновационно-инвестиционных проектов и кластерных инициатив в области переработки вторичных молочных ресурсов.

Существенное значение для оценки успешного функционирования кластера имеют также вспомогательные инструменты наблюдения за процессом кластеризации: периодическое интервьюирование участников кластера, разработка и применение специализированных форм отчетности.

\section{ВЫВОДЫ}

1. В качестве организационного инструмента повышения эффективности использования вторичных молочных ресурсов предлагается реализация кластерного подхода в сочетании с делегированным самоуправлением бизнеса, предполагающим создание в Республике Беларусь кластера переработки вторичных молочных ресурсов под руководством саморегулируемой организации. С одной стороны, организация кластера использования вторичных молочных ресурсов затрагивает национальные интересы Республики Беларусь. С другой - существуют неблагоприятные факторы деловой среды, препятствующие самостоятельному появлению устойчивых сетей взаимодействия: доминирование государства над наукой и бизнесом при отсутствии обратных связей, узость поля горизонтальных связей, высокий уровень сопротивления изменениям и крайняя разобщенность социума. Кроме того, в международной практике набирают популярность «золотые правила» кластерной политики, сформулированные К. Кетельсом, одно из которых утверждает, что государство не должно селективно отбирать потенциальных участников кластеров, их проекты и на конкурсной основе определять приоритеты для целей субсидирования. В связи с этим для экономики Республики Беларусь на текущем этапе наиболее целесообразным является нисходящий путь организации кластера, предполагающий инициирование его создания, а также поддержку и содействие на первых этапах жизненного цикла государственными органами управления.

2. Возможны два основных сценария создания кластера использования вторичных молочных ресурсов в Республике Беларусь: дирижистский и либеральный. Оба сценария предполагают инициирование процесса кластеризации «сверху-вниз». Дирижистский путь создания кластера позволяет преодолеть на начальных этапах феномен сопротивления инновациям, однако, он сопряжен с проблемой формального отношения бизнеса к процессам кластеризации. Предпочтительным является либеральный путь, основанный на диалоге корпоративного и государственного уровней управления, который позволяет уже на начальных этапах кластеризации реализовать наиболее оптимальную модель создания смешанного кластера.

3. Наиболее предпочтительной формой организации кластера использования вторичных молочных ресурсов является простое товарищество, поскольку:

- кластер объединяет большое количество как коммерческих, так и некоммерческих организаций;

- базовые и структурообразующие отрасли-участники кластера относятся к различным цепочкам создания добавленной стоимости;

- между участниками кластера могут возникать разнообразные экономические, как вертикальные, так и горизонтальные связи;

- некоторые структурообразующие отрасли-участники кластера никак между собой не взаимодействуют.

4. Организация в Республике Беларусь кластера использования вторичных молочных ресурсов с ключевой ролью предприятий по централизованной переработке предполагает разработку и применение кластерной политики, направленной на содействие и поддержку кластерных инициатив в обозначенном направлении. В распоряжении государственных органов управления имеется разнообразный инструментарий поддержки, содействия и стимулирования бизнеса с целью его вовлечения в интеграционные процессы. Ключевые роли государственных органов управления в стимулировании кластерной инициативы включают: управление сопротивлением инновациям; стимулирование предпринимательской инициативы и активизация инновационной деятельности на основе содействия и поддержки; реор- 
ганизация инфраструктурной системы поставки услуг; реорганизации системы представления экономической информации; создание сети организаций инновационного развития; целевая подготовка квалифицированных кадров; установление связей между учреждениями образования и центрами кластерного развития; формирование развитых экспортных сетей; защита внутреннего рынка.

\section{ЛИТЕРАТУРА}

1. Martina Fromhold-Eisebith, Gunter Eisebith. How to institutionalize innovative clusters? Comparing explicit topdown and implicit bottom-up approaches M. Fromhold-Eisebith, G. Eisebith // Research Policy. - 2005. - № 34. - p. 12501268

2. Смородинская, Н.В. Территориальные инновационные кластеры: мировые ориентиры и российские реалии // Высшая школа экономики [Электронный pecypc].- 2013. - Режим доступа: $\underline{\text { http://www.hse.ru/data }}$ /2013/04/11/1297354387/ Smorodinskaya.pdf. - Дата доступа: 20.06.2015.

3. Guidelines for Cluster Development, A Handbook for Practitioners // Republic of Croatia Ministry of Entrepreneurship and Crafts [Electronic resource]. $-\quad$ June 2013. - Mode of access: http://www.minpo.hr/UserDocsImages/Podr\%C5\%A1ka\%20razvoju\%20klastera /4.Smjernice \%20za\%20razvoj\%20klastera.pdf. - Date of access: 20.06.2015.

4. Об утверждении Концепции формирования и развития инновационно-промышленных кластеров в Республике Беларусь и мероприятий по ее реализации: постановление Совета Министров Республики Беларусь от 16 января 2014 г. № 27 // Национальный реестр правовых актов Республики Беларусь. - 23.01.2014. - 5/38322

Статья поступила в редакциию 8 июля 2015 года. 